\title{
High levels of Notch intracellular cleaved domain are associated with stemness and reduced bevacizumab efficacy in patients with advanced colon cancer
}

\author{
FRANCESCA NEGRI $^{1 *}$, CECILIA BOZZETTI $^{1 *}$, GIUSEPPE PEDRAZZI ${ }^{2}$, CINZIA AZZONI $^{3}$, \\ LORENA BOTTARELLI ${ }^{3}$, ANNA SQUADRILLI ${ }^{1}$, COSTANZA LAGRASTA ${ }^{3}$, IONE TAMAGNINI ${ }^{4}$, \\ ALESSANDRA BISAGNI ${ }^{4}$, MOIRA RAGAZZI $^{4}$, ROSA PORZIO ${ }^{5}$, GIANLUCA TOMASELLO ${ }^{6}$, \\ DANIELE MORI $^{7}$, FRANCESCO LEONARDI $^{1}$, LETIZIA GNETTI $^{3}$, PELLEGRINO CRAFA $^{3}$, \\ ROBERTO SALA $^{7}$ and STEFANO CASCINU ${ }^{8}$
}

${ }^{1}$ Medical Oncology Unit, University Hospital of Parma; ${ }^{2}$ Department of Medicine and Surgery, Unit of Neuroscience and Robust Statistics Academy (Ro.S.A.), University of Parma; ${ }^{3}$ Department of Medicine and Surgery,

Unit of Pathological Anatomy, University Hospital of Parma, I-43126 Parma; ${ }^{4}$ Pathology Unit,

Istituto di Ricerca e Cura a Carattere Scientifico (IRCCS), Santa Maria Nuova Hospital, I-42123 Reggio Emilia;

${ }^{5}$ Department of Oncology-Haematology, G. da Saliceto Hospital, I-29121 Piacenza; ${ }^{6}$ Medical Oncology Unit, ASST Ospedale di Cremona, I-26100 Cremona; ${ }^{7}$ Department of Medicine and Surgery, General Pathology, University of Parma, I-43126 Parma; ${ }^{8}$ Division of Medical Oncology, University Hospital of Modena and Reggio Emilia, I-41124 Modena, Italy

Received October 10, 2018; Accepted May 31, 2019

DOI: 10.3892/or.2019.7349

\begin{abstract}
DLL4)-Notch signaling is associated with tumor resistance to anti-vascular endothelial growth factor (VEGF) therapy. Furthermore, Notch signaling is critical for the maintenance of colon cancer stem cells (CSCs), which are relevant in drug resistance and tumor angiogenesis. CD44 is a transmembrane glycoprotein and is considered a putative marker of CSCs. To assess the association of Notch intracellular cleaved domain (NICD), DLL4 and CD44 expression with the efficacy of anti-angiogenic drugs, a series of samples derived from patients with advanced colon cancer enrolled in prospective clinical trials were analyzed. Histological samples from 51 primary tumors that originated from patients treated with bevacizumab-based first-line chemotherapy were analyzed by immunohistochemistry for NICD, DLL4 and CD44 expression, and CD31 for microvessel count. The expression levels of genes relevant for angiogenesis [angiopoietin (ANGPT)1, ANGPT2, fibroblast growth factor $(F G F) 1, F G F 2$, epidermal grow th factor, placental growth factor, VEGFA and DLL4] were detected by reverse transcription-quantitative PCR using RNA extracted
\end{abstract}

Correspondence to: Dr Francesca Negri, Medical Oncology Unit, University Hospital of Parma, Via Gramsci 14, I-43126 Parma, Italy E-mail: francescanegri2@hotmail.com

*Contributed equally

Key words: colon cancer, bevacizumab, Notch, $\delta$-like ligand 4, CD44, cancer stem cells, angiogenesis from the frozen tissues of four tumors with low and four tumors with high NICD expression. Strong NICD levels were observed in $12 / 51(24 \%)$ of the patients, whereas $16 / 51(31 \%)$ of the colon cancer subjects exhibited high CD44 expression. Strong CD44 staining was associated with high NICD levels compared with the CD44 expression levels noted in samples with low NICD levels (67 vs. $20 \%, \mathrm{P}=0.005)$. No association was observed with regards to the expression levels of NICD, CD44 and the other aforementioned biomarkers. High expression levels of NICD and CD44 predicted reduced progression-free survival $(\mathrm{P}<0.001)$ and overall survival $(\mathrm{P}=0.002)$. No significant differences in the expression of angiogenesis-related genes were detected between low and high NICD-expressing tumors. In conclusion, NICD and CD44 tissue levels exhibited an association and may be related to a reduced survival rate in patients with advanced colon cancer treated with bevacizumab.

\section{Introduction}

Bevacizumab is a humanized monoclonal antibody (mAb) that targets vascular endothelial growth factor (VEGF). It was the first anti-angiogenic drug approved for the treatment of metastatic colorectal cancer (CRC) (1). Despite its prompt and successful development, acquired tumor resistance (2) limits the clinical efficacy of bevacizumab $(1,3,4)$.

Previous studies have indicated that CRC may originate from an uncommitted population of cancer cells defined as cancer stem cells (CSCs), which are responsible for self-renewal, multipotentiality and resistance to apoptosis (5-10). These cells may serve a role in the failure of patients to respond to anti-cancer treatment $(11,12)$. Notably, Notch components colocalize with stem cell markers near the base of crypts where intestinal stem cells 
reside (5), thus suggesting that Notch signaling participates in the regulation of uncommitted intestinal cell precursors $(13,14)$.

Notch is activated via the binding of its ligands, including Notch $\delta$-like ligand 4 (DLL4), leading to the proteolytic cleavage of this protein by $\gamma$-secretase and the production of an active form of the molecule known as Notch intracellular cleaved domain (NICD) (15). NICD translocates from the cytoplasm to the nucleus and binds to nuclear factors, in order to regulate the expression of Notch target genes (16). A previous in vivo study (17) indicated that DLL4-induced Notch signaling mediates tumor resistance to bevacizumab. In accordance with these data, our previous study reported that high expression levels of tissue NICD are correlated with resistance to anti-VEGF treatment (18).

CD44 is a well-recognized putative CSC marker used in colon cancer. This protein is a hyaluronic receptor that promotes cell-matrix adhesion, thus enhancing cellular aggregation and tumor growth (19-21). SW480 colon cancer cells with high CD44 expression are enriched with markers of chemoresistance (22) and exhibit activation of signaling pathways, such as Notch, Wnt and transforming growth factor- $\beta$ /bone morphogenetic protein (23).

The present study used immunostaining to measure the expression levels of DLL4 and CD44 in tissue samples from patients with metastatic colon cancer treated with bevacizumab in first-line clinical trials; the same patients had previously been tested for NICD expression. In addition, intratumor microvessel density (MVD) was assessed by evaluating the endothelial cell marker CD31, and in a limited number of available frozen samples, the expression of a set of angiogenesis-related genes was detected (24). The aim of the present study was to assess the possible role of CD44 and DLL4 expression, alongside the tissue levels of NICD, on clinical outcomes.

\section{Materials and methods}

Patients. This study performed a retrospective analysis of 51 patients with histologically confirmed metastatic colon cancer who were treated with first-line bevacizumab-based chemotherapy. The study group consisted of patients with metastatic colon cancer who were previously enrolled to four prospective clinical trials (25-28) at four cancer centers in Italy (Medical Oncology Units of University Hospital of Parma, Parma, Italy; Santa Maria Nuova Hospital, Reggio Emilia, Italy; Azienda USL, Piacenza, Italy; and Istituti Ospitalieri, Cremona, Italy), between August 2005 and November 2011. These trials assessed first-line treatment with bevacizumab plus chemotherapy in patients with advanced CRC and had similar eligibility criteria (25-28). In all patients, adequate formalin-fixed paraffin-embedded samples from the primary tumor obtained prior to treatment were available; seven biopsies and 44 resection specimens were available. The patients received $5 \mathrm{mg} / \mathrm{kg}$ bevacizumab intravenously every 2 weeks or an intravenous injection of $7.5 \mathrm{mg} / \mathrm{kg}$ bevacizumab every 3 weeks until the incidence of unacceptable adverse events, radiological progression, as defined by Response Evaluation Criteria in Solid Tumors (RECIST; version 1.1) (29), or patients' withdrawal. The clinical variables considered for outcome analysis were as follows: Progression-free survival (PFS), overall survival (OS) and response rate (RR).
The present study was performed in accordance with a protocol (reference number 5065) approved by the institutional review board/independent ethics committee of the University Hospital of Parma. All patients provided written informed consent for their participation in the study.

Immunohistochemistry. Tumor specimens were routinely fixed in $4 \%$ buffered formalin at room temperature for $\geq 24 \mathrm{~h}$ and embedded in paraffin. The sections $(5 \mu \mathrm{m})$ were then stained with hematoxylin and eosin for histological diagnosis. In order to allow a precise and accurate immunohistochemical evaluation of the markers, the most representative section of each tumor with intact tumor cells was chosen, excluding necrotic areas, i.e. the section where it was possible to evaluate both grading and tumor morphology. For antigen retrieval prior to antibody incubation, the sections were treated with $10 \mathrm{mM}$ citrate buffer ( $\mathrm{pH}$ 6.0) in a $750 \mathrm{~W}$ microwave oven for three 5 -min cycles. The sections were incubated overnight at $4^{\circ} \mathrm{C}$ with the following primary antibodies: NICD (Val1744) polyclonal antibody (1:50; cat. no. 2421; Cell Signaling Technology, Inc.), CD44 mAb (1:50; clone DF1485; cat. no. m708201-2; Dako; Agilent Technologies, Inc.), DLL4 polyclonal antibody (1:50; cat. no. HPA023392; Sigma-Aldrich; Merck KGaA) and CD31 mAb (1:50; clone JC70; cat. no. 760-4378; Ventana Medical Systems, Inc.). Following primary antibody incubation, sections were immunostained with ADVANCE horseradish peroxidase (HRP) Link (cat. no. K4068; Dako; Agilent Technologies, Inc.), at room temperature for $30 \mathrm{~min}$ and detected with ADVANCE HRP Enzyme (Dako; Agilent Technologies, Inc.) at room temperature for $30 \mathrm{~min}$, followed by incubation with DAB (3-10 min at room temperature) as a substrate-chromogen and hematoxylin as a counterstain (1 min at room temperature). Samples were observed using a light microscope.

Immunostaining for NICD and CD44 was semi-quantified using an intensity score as follows: Weak (1+), moderate (2+) or strong (3+). The expression levels of NICD and CD44 were considered positive when strong staining (3+) was noted in $>50 \%$ (high NICD) (18) and $\geq 60 \%$ (high CD44) of cells, respectively. DLL4 expression was semi-quantitatively scored on a scale from 0 (no vessels stained) to 3 (nearly all vessels stained) when considering the entire tissue section. CD31 immunostaining for blood vessel density was evaluated by observing each slide at x200 magnification to identify hotspots of angiogenesis. The microvessel count was obtained from a minimum of four to a maximum of 12 fields at $\mathrm{x} 400$ magnification corresponding to a tumor area of $2.3 \mathrm{~mm}^{2}$ per field. For each sample, microvessels were counted in four separate areas of highest vascularity and the average value of these four fields was used to evaluate the MVD. Any single endothelial cell or small cluster of endothelial CD31-positive cells was counted as a single microvessel, even in the absence of a visible vascular lumen (30).

For each antibody tested, bovine serum albumin (Sigma-Aldrich; Merck KGaA) was used in place of the primary antibody as a negative control. Positive controls included positive samples that had previously been tested for each antibody. In presence of a doubtful result, the test was repeated on another section. The histopathological slides from all patients were evaluated independently by two observers blinded to the patient data and clinical outcomes. 
Table I. Reverse transcription-quantitative polymerase chain reaction primer sequences.

\begin{tabular}{lllcc}
\hline Gene & \multicolumn{1}{c}{ Forward primer (5'-3') } & \multicolumn{1}{c}{ Reverse primer (5'-3') } & $\begin{array}{c}\text { Annealing } \\
\text { temperature }\left({ }^{\circ} \mathrm{C}\right)\end{array}$ & $\begin{array}{c}\text { Amplicon } \\
\text { size }(\mathrm{bp})\end{array}$ \\
\hline ANGPT1 & AGAACCACACGGCTACCA & CATTTGTCTGTTGAAGAAGTTGCT & 59 & 186 \\
ANGPT2 & CGGCTGTGATGATAGAAATAGGG & GAAGTTCAAGTCTCGTGGTCTG & 59 & 114 \\
$D L L 4$ & GCCAACTATGCTTGTGAATGTC & TAGGTGCCCGTGAATCCA & 59 & 158 \\
$E G F$ & GCTGCTCACTCTTATCATTCTGTT & TGGTTCCTTCTGTGTCAATCCTA & 59 & 191 \\
$F G F 1$ & GAGCGACCAGCACATTCAG & GTTCTCCTCCAGCCTTTCCA & 59 & 166 \\
$F G F 2$ & AGAAGAGCGACCCTCACATCA & ACTGCCCAGTTCGTTTCAGTG & 59 & 237 \\
$P G F$ & CGTCAGAGGTGGAAGTGGTA & CAGCAGGGAGACACAGGAT & 59 & 140 \\
$R P L 15$ & GCAGCCATCAGGTAAGCCAAG & AGCGGACCCTCAGAAGAAAGC & 59 & 100 \\
$V E G F A$ & CAGAAGGAGGAGGGCAGAA & ACACAGGATGGCTTGAAGATG & 59 & 145 \\
\hline
\end{tabular}

$A N G P T$, angiopoietin; $D L L 4, \delta$-like ligand 4; EGF, epidermal growth factor; $F G F$, fibroblast growth factor; $P G F$, placental growth factor; $R P L 15$, ribosomal protein L15; VEGFA, vascular endothelial growth factor A.

Gene expression analysis. As this was a retrospective study, RNA analysis was performed only on the available frozen tissue samples with a good RNA quality. Briefly, $50 \mathrm{mg}$ frozen tissue fragments from four tumors with high NICD expression and four tumours with low NICD expression were collected and stored in RNAse-later solution for $\leq 24 \mathrm{~h}$ prior to RNA extraction. The RNAse-later solution was subsequently replaced with $1 \mathrm{ml}$ TRIzol ${ }^{\circledR}$ for RNA isolation (Invitrogen; Thermo Fisher Scientific, Inc.), and a 125-W CAT X120 handheld Homogenizer (Ingenieurbüro CAT, M. Zipperer GmbH) was used for tissue homogenization at 22,000 rpm. Total RNA was isolated from the homogenized samples in TRIzol ${ }^{\circledR}$ solution according to the manufacturer's protocol, and was quantified by Nanodrop 2000 (NanoDrop Technologies; Thermo Fisher Scientific, Inc.).

Reverse transcription-quantitative PCR (RT-qPCR) amplification. A total of $1 \mu \mathrm{g}$ RNA was reverse transcribed with a mixture of random hexamer oligonucleotides using a Reverse Transcription system kit (Promega Corporation), according to the manufacturer's protocol. Subsequently, cDNA was incubated in a mixture composed of $2 X_{\text {GoTaq }}{ }^{\circledR}$ qPCR Master Mix (Promega Corporation), 5 pmol specific primers and RNase-free water. A total of 40 cycles of amplification were performed in a thermal cycler (Rotor Gene 3000 5.0.06 version; Corbett Life Science; Qiagen, Inc.). For amplification, the first cycle included a denaturation step at $95^{\circ} \mathrm{C}$ for $15 \mathrm{sec}$, followed by an annealing step at $59^{\circ} \mathrm{C}$ for $15 \mathrm{sec}$ and an extension step at $72^{\circ} \mathrm{C}$ for $15 \mathrm{sec}$. The cycles were repeated 40 times; prior to the 40 cycles, samples underwent initial denaturation at $95^{\circ} \mathrm{C}$ for $2 \mathrm{~min}$, and after the 40 cycles, samples underwent final extension at $72^{\circ} \mathrm{C}$ for $30 \mathrm{sec}$.

The primer pairs for angiopoietins (ANGPT1, ANGPT2), fibroblast growth factor $(F G F 1, F G F 2)$, placental growth factor $(P G F), V E G F, D L L 4$, ribosomal protein L15 (RPL15) and epidermal growth factor $(E G F)$ detection were designed using the Primer-BLAST tool (National Center for Biotechnology Information) (Table I) and were synthesized by Sigma-Aldrich; Merck KGaA.

The melting curve was assessed for each amplified gene and the data were normalized based on the reference gene
RPL15; the results were analyzed with the Relative Expression Software Tool $\left(\mathrm{REST}^{\circ}\right.$ ) (30). Relative expression was calculated as follows: Relative expression=concentration of the gene of interest/concentration of RPL15. To determine the difference in expression between high and low NICD groups, according to REST software, the relative expression ratio was calculated using to the following formula: Relative expression ratio=efficiency of

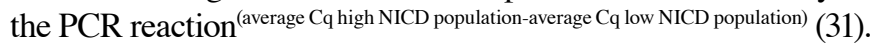

Statistical analysis. All statistical analyses were performed using SPSS v.23 software (IBM Corp.) and/or R v.3.5.1, including several additional packages from CRAN (Comprehensive R Archive Network; cran.r-project.org). The Pearson's $\chi^{2}$ and Fisher's exact test were used to evaluate the association between categorical variables in contingency tables. $\mathrm{P}<0.05$ was considered to indicate a statistically significant difference. A receiver operating characteristic (ROC) curve analysis was performed on CD44 levels to determine a possible cut-off criterion for CD44 expression and tumor response to bevacizumab. Binary logistic regression was used to investigate the association between RR and various predictors.

The mean and median time for PFS and OS were investigated using the Kaplan-Meier product-limit estimator. Log-rank test was used to ascertain statistical significance. Cox regression analysis was then performed in order to estimate the association of PFS and OS with the covariates in a multivariable context.

The screening of variables and the selection of covariates for Cox regression were performed according to previous studies by Hosmer et al (32) and Mills (33). The process can be summarized as follows: i) All the variables that were determined significant $(\mathrm{P}=0.20-0.25)$ by a previous univariate analysis (Kaplan-Meier or others), and those considered significant from a theoretical point of view and from previous research, were added to the model. The variables that were deemed significant (i.e. $\mathrm{P}=0.20-0.25$ ) were included in order to incorporate variables with the potential of being important confounders; ii) the variables identified in step i) were fit in a multivariate model, and backward selection was used to eliminate non-significant variables at $\mathrm{P}=0.10$; iii) each of the 
Table II. Patient characteristics.

\begin{tabular}{|c|c|c|c|}
\hline Characteristic & Low-NCID & High-NCID & P-value \\
\hline $\mathrm{N}$ & $39 / 51(76 \%)$ & $12 / 51(24 \%)$ & \\
\hline Mean age, years (SD) & $64.1(9.8)$ & $62.9(14.8)$ & 0.794 \\
\hline Age range & $36-79$ & $37-81$ & \\
\hline \multicolumn{4}{|l|}{ Sex } \\
\hline Male & $23 / 39(59 \%)$ & $6 / 12(50 \%)$ & 0.741 \\
\hline Female & $16 / 39(41 \%)$ & $6 / 12(50 \%)$ & \\
\hline \multicolumn{4}{|l|}{$\mathrm{CEA}, \mathrm{ng} / \mathrm{ml}$} \\
\hline$\leq 30$ & $22 / 37(44 \%)$ & $5 / 11(45 \%)$ & \\
\hline$>30$ & $15 / 37(56 \%)$ & $6 / 11(55 \%)$ & 0.498 \\
\hline Unknown & 2 & 1 & \\
\hline \multicolumn{4}{|l|}{$K R A S$} \\
\hline Mutant & $11 / 27(41 \%)$ & $8 / 11(73 \%)$ & \\
\hline Wild-type & $16 / 27(59 \%)$ & $5 / 12(42 \%)$ & 0.151 \\
\hline Unknown & 12 & 1 & \\
\hline \multicolumn{4}{|l|}{ Number of metastatic sites } \\
\hline 1 & $26 / 39(67 \%)$ & $7 / 12(58 \%)$ & \\
\hline$\geq 2$ & $13 / 39(33 \%)$ & $5 / 12(42 \%)$ & 0.732 \\
\hline \multicolumn{4}{|l|}{ First-line chemotherapy regimens } \\
\hline FOLFIRI + bevacizumab & $17 / 39(44 \%)$ & $2 / 12(17 \%)$ & 0.171 \\
\hline FOLFOXIRI + bevacizumab & $9 / 39(23 \%)$ & $6 / 12(50 \%)$ & 0.144 \\
\hline FOLFOX + bevacizumab & $8 / 39(20 \%)$ & $2 / 12(17 \%)$ & 0.999 \\
\hline Capecitabine + bevacizumab & $4 / 39(10 \%)$ & $1 / 12(8 \%)$ & 0.999 \\
\hline CAPEOX + bevacizumab & $0 / 39 \quad(0 \%)$ & $1 / 12(8 \%)$ & 0.235 \\
\hline CAPIRI + bevacizumab & $1 / 39 \quad(3 \%)$ & $0 / 12(0 \%)$ & 0.999 \\
\hline \multicolumn{4}{|l|}{ Subsequent chemotherapy } \\
\hline Yes & $26 / 39(67 \%)$ & $9 / 12(75 \%)$ & \\
\hline Received cetuximab & $13 / 39(33 \%)$ & $3 / 12(25 \%)$ & 0.730 \\
\hline Positive CD44 & $8 / 39(20 \%)$ & $8 / 12(67 \%)$ & 0.005 \\
\hline Positive DLL4 & $12 / 31(39 \%)$ & $7 / 10(70 \%)$ & 0.144 \\
\hline Mean CD31 (SD) & $51.2(25.7)$ & $40.8(17.9)$ & 0.243 \\
\hline Median MVD, per $\mathrm{mm}^{2}$ (range) & $22.2(4.8-51.3)$ & $15.7(9.6-31.3)$ & 0.301 \\
\hline
\end{tabular}

DLL4, $\delta$-like ligand 4; MVD, microvessel density; NICD, Notch intracellular cleaved domain.

non-significant variables from step i) were added back, one at a time, using forward stepwise selection (with significance level $\mathrm{P}=0.05$ for entry and $\mathrm{P}=0.10$ for removal) in order to confirm that the variables were not statistically significant and that they did not function as a key confounder. At that stage, it was possible to add interactions between any of the main effects in the model. iv) The entire model was evaluated by undertaking model diagnostics. This included checking for the overall goodness-of-fit, model adherence to key assumptions, influential observations and nonlinearity. The variables considered in the Cox regression were as follows: KRAS, type of chemotherapy protocol, second-line treatment, NICD and CD44 expression; only NICD and C44 expression were maintained in the final model.

The regression coefficients were reported as hazard ratios (HRs). The 95\% confidence intervals (CIs) were also estimated from the analysis. All P-values obtained from the survival analysis were corrected for multiple comparisons using the Bonferroni correction.

\section{Results}

NICD and CD44 expression. The relevant patient characteristics are shown in Table II. NICD immunostaining was predominantly localized in the cytoplasm (Fig. 1A). A total of 12 out of the $51(24 \%)$ cases exhibited a strong (score $3+\geq 50 \%$ of tumor cells) expression score, whereas $39(76 \%)$ exhibited a low NICD expression score (two cases exhibited negative staining, nine weak and 28 moderate). CD44 staining (Fig. 1B) was mainly localized to the membrane of the epithelial tumor cells. The threshold for differentiating between responders and non-responders was set at $\geq 60 \%$ of the tumor cells showing CD44 intensity of 3+ (Fig. 2). The cut-off was obtained by the Youden's index and by the minimum 
Table III. Association between NICD and CD44 expression in patients with colon cancer.

\begin{tabular}{lcc}
\hline Expression & Low NICD & High NICD \\
\hline Low CD44 & 31 & 4 \\
High CD44 & 8 & 8 \\
\hline
\end{tabular}

Fisher's exact test, $\mathrm{P}=0.005$; $\mathrm{Phi}=0.422, \mathrm{P}=0.003$; Cramer's $\mathrm{V}=0.422$, $\mathrm{P}=0.003$; Contingency Coefficient $\mathrm{C}=0.389, \mathrm{P}=0.003$. NICD, Notch intracellular cleaved domain.

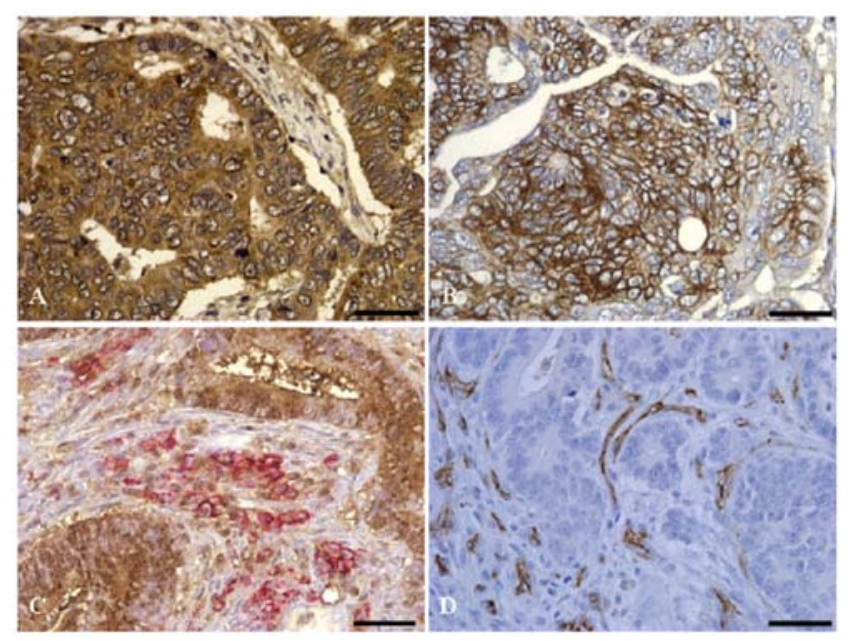

Figure 1. Immunohistochemical staining of NICD, CD44 and CD31 proteins in colon carcinoma samples. (A) NICD cytoplasmic reactivity; (B) CD44 membranous staining; (C) double immunostaining for NICD (brown) and CD44 (red); (D) CD31 positive expression in vascular endothelial cells. Scale bars, $50 \mu \mathrm{m}$. NICD, Notch intracellular cleaved domain.

distance from the coordinates $(0,1)$ in the ROC plot. The value that optimized sensitivity and specificity was found to be $55 \%$. Since the limited precision of staining resulted in the expression of staining data as multiples of 10 , values equal or greater than $60 \%$ were considered to indicate positive staining. A total of 16 out of 51 patients (31\%) exhibited strong CD44 staining. High NICD levels were significantly associated with high CD44 staining (67 vs. 20\%, P=0.005) (Table III; Fig. 1C). Membranous and/or cytoplasmic expression of DLL4 was observed in tumor-associated vessels, and in large and small size peritumoral vessels (data not shown). Strong DLL4 staining was observed in 19 out of 41 (46\%) cases.

CD31 immunoreactivity was localized to vascular endothelial cells in 40 samples evaluated for CD31 expression (Fig. 1D). The observed MVD values ranged between 11 and 118 per $\mathrm{mm}^{2}$ at $\mathrm{x} 40$ magnification (median value, 19.6 per $\mathrm{mm}^{2}$ ). Neither DLL4 nor CD31 expression was associated with NICD or CD44 levels (Table II).

No significant differences were noted in the relevant clinical features examined (specifically, age, baseline carcinoembryonic antigen levels, KRAS mutation status, metastatic sites and sequential lines of therapy) among the patient subgroups (Table II).

NICD/CD44 expression and clinical outcome. Patients with tumors exhibiting high NICD and high CD44 expression



Figure 2. Receiver operating characteristic curve analysis of CD44 expression levels: Area under the curve, $0.852 ; 95 \%$ confidence interval, $0.710-0.994$. The model was based on CD44 staining following tumor response to the action of bevacizumab.
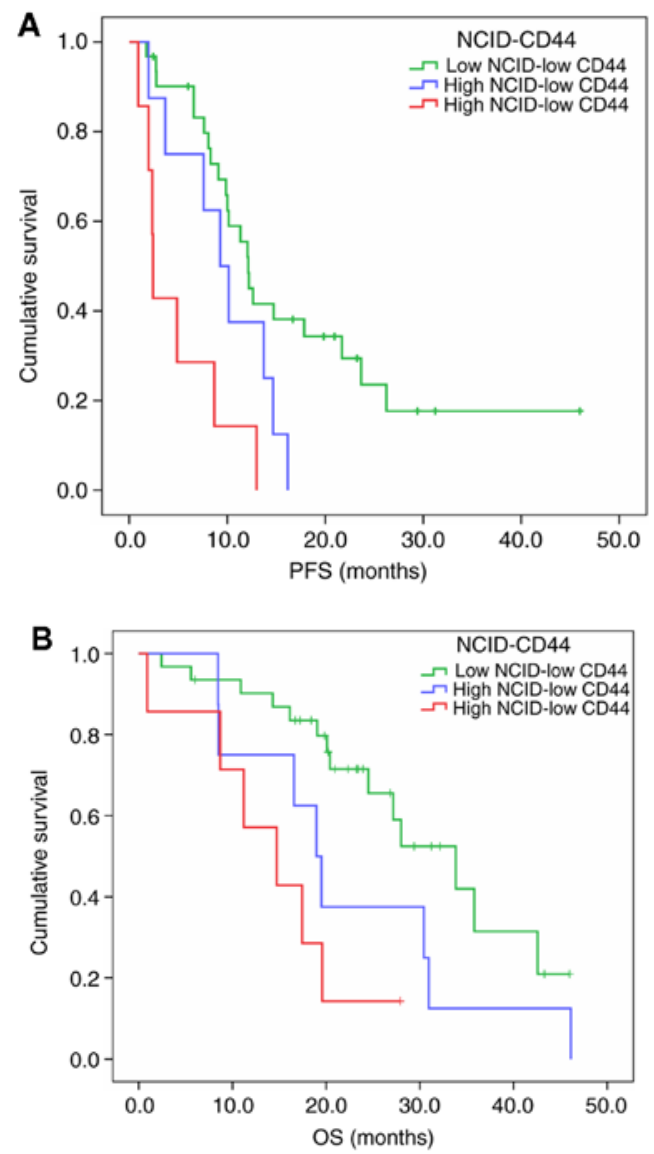

Figure 3. (A) PFS and (B) OS curves associated with NICD and CD44 expression. NICD, Notch intracellular cleaved domain; OS, overall survival; PFS, progression-free survival.

exhibited a significantly shorter PFS (median PFS 2.3 vs. 12.1 months; $\mathrm{P}<0.001$ ) and OS (median OS 14.7 months vs. 33.8 months; $\mathrm{P}=0.002$ ) compared with those noted in the patients with low levels of NICD and CD44 expression (Fig. 3A and B). Cox regression confirmed the role of NICD and CD44 expression in the prediction of OS and PFS. Table IV indicated that the HR increased significantly from low to high NICD and CD44 expression groups. 
Table IV. Cox regression coefficients for PFS and OS relative to NICD and CD44 expression.

\begin{tabular}{|c|c|c|c|c|c|c|}
\hline \multirow[b]{2}{*}{ Expression } & \multicolumn{3}{|c|}{ PFS } & \multicolumn{3}{|c|}{ OS } \\
\hline & HR $(95 \%$ CI $)$ & P-value & $\begin{array}{c}\text { Corrected } \\
\text { P-value }^{\mathrm{a}}\end{array}$ & $\mathrm{HR}(95 \% \mathrm{CI})$ & P-value & $\begin{array}{c}\text { Corrected } \\
\text { P-value }^{\mathrm{a}}\end{array}$ \\
\hline NICD-Low; CD44-Low & RV & 0.001 & & RV & 0.050 & \\
\hline NICD-Low; CD44-High & $2.21(0.82-5.92)$ & 0.117 & 0.351 & $1.39(0.47-4.17)$ & 0.554 & 1.00 \\
\hline NICD-High; CD44-Low & $2.43(0.98-6.04)$ & 0.057 & 0.171 & $2.21(0.80-0.10)$ & 0.126 & 0.378 \\
\hline NICD-High; CD44-High & $4.63(1.70-12.7)$ & 0.003 & 0.009 & $4.26(1.35-13.5)$ & 0.014 & 0.042 \\
\hline
\end{tabular}

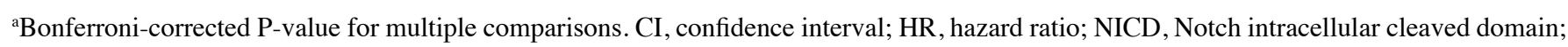
$\mathrm{RV}$, reference value.

Table V. Response rate and main clinicopathological characteristics.

\begin{tabular}{lcc}
\hline Characteristics & SD + PR + CR & PD \\
\hline $\mathrm{N}$ & $40 / 51(78 \%)$ & $11 / 51(22 \%)$ \\
Mean age, years (SD) & $65.1(10.5)$ & $59.2(12.1)$ \\
Age range & $36-81$ & $37-75$ \\
Sex & & \\
Male & $23 / 40(57 \%)$ & $6 / 11(54 \%)$ \\
Female & $17 / 40(43 \%)$ & $5 / 11(46 \%)$ \\
CEA, ng/ml & & $4 / 9(44 \%)$ \\
$\quad \leq 30$ & $23 / 39(59 \%)$ & $5 / 9(56 \%)$ \\
$>30$ & $16 / 39(41 \%)$ & \\
KRAS & & $8 / 11(73 \%)$ \\
Mutant & $11 / 27(41 \%)$ & $3 / 11(27 \%)$ \\
Wild-type & $16 / 27(59 \%)$ & $8 / 11(73 \%)$ \\
Positive CD44 & $8 / 40(20 \%)$ & $7 / 11(64 \%)$ \\
Positive NICD & $5 / 40(12 \%)$ & $6.999(67 \%)$ \\
Positive DLL4 & $13 / 32(41 \%)$ & $35.7(13.8)$ \\
Mean CD31 (SD) & $51.4(25.2)$ & $11.7(10.9-23.9)$ \\
Median MVD, per mm ${ }^{2}$ (range) & $20.0(4.8-51.3)$ & 0.477 \\
\hline
\end{tabular}

CEA, carcinoembryonic antigen; CR, complete response; DLL4, $\delta$-like ligand 4; MVD, microvessel density; NICD, Notch intracellular cleaved domain; PD, progressive disease; PR, partial response; SD, stable disease.

Table VI. Statistically significant variables after binary logistic regression.

\begin{tabular}{lrrrrrr}
\hline Variable & B & S.E. & Wald & df & P-value & OR (95\% CI) \\
\hline Constant & -2.786 & .689 & 16.340 & 1 & $<0.001$ & $0.062(0.016-0.238)$ \\
NICD (high vs. low) & 1.939 & .858 & 5.110 & 1 & 0.024 & $6.951(1.294-37.341)$ \\
CD44 (high vs. low) & 1.817 & .854 & 4.529 & 1 & 0.033 & $6.153(1.154-32.790)$ \\
\hline
\end{tabular}

Dependent variable, response rate. Methods include forward, backward and stepwise elimination. CI, confidence interval; NICD, Notch intracellular cleaved domain; OR, odds ratio.

In the positive (high NICD) group, the RR (complete response, partial response and stable disease) was $12 \%$, whereas $64 \%$ of patients exhibited progressive disease $(\mathrm{P}=0.001$;
Table V). Among the patients with high CD44 expression, the RR (complete response, partial response and stable disease) was estimated to be $20 \%$, whereas progressive disease was 
Table VII. Statistical analysis of gene expression levels between the high and low NICD groups.

A, RPL15 expression in high NICD vs. low NICD groups

\begin{tabular}{lcccc}
\hline Gene & Reaction efficiency & Relative expression ratio & S.E. & 95\% CI \\
\hline RPL15 & 1.0 & 0.847 & $0.563-1.217$ & $0.398-1.995$ \\
\hline
\end{tabular}

B, Expression in high NICD vs. low NICD groups ${ }^{\mathrm{a}}$

\begin{tabular}{|c|c|c|c|c|c|}
\hline Gene & Reaction efficiency & Relative expression ratio & S.E. & $95 \% \mathrm{CI}$ & P-value \\
\hline$A N G P 1$ & 1.0 & 1.112 & $0.335-5.329$ & $0.211-11.404$ & 0.893 \\
\hline$A N G P 2$ & 1.087 & 0.562 & $0.27-1.09$ & $0.185-2.867$ & 0.324 \\
\hline$D L L 4$ & 0.83 & 0.880 & $0.132-7.965$ & $0.028-23.115$ & 0.976 \\
\hline$E G F$ & 0.7 & 1.218 & $0.649-3.100$ & $0.307-4.639$ & 0.773 \\
\hline$F G F 1$ & 0.91 & 0.868 & $0.206-3.172$ & $0.150-7.659$ & 0.866 \\
\hline$F G F 2$ & 0.76 & 0.868 & $0.522-1.314$ & $0.411-2.074$ & 0.587 \\
\hline$P G F$ & 0.94 & 0.313 & $0.040-3.314$ & $0.0006-23.860$ & 0.381 \\
\hline$V E G F A$ & 0.83 & 1.684 & $0.612-3.232$ & $0.427-8.722$ & 0.333 \\
\hline
\end{tabular}

${ }^{a}$ Results were normalized to the housekeeping gene RPL15. ANGPT, angiopoietin; CI, confidence interval; DLL4, $\delta$-like ligand 4; EGF, epidermal growth factor; $F G F$, fibroblast growth factor; NICD, Notch intracellular cleaved domain; $P G F$, placental growth factor; $R P L 15$, ribosomal protein L15; VEGFA, vascular endothelial growth factor A.

observed in $73 \%$ of the patients $(\mathrm{P}=0.002$; Table $\mathrm{V})$. Results of the binary logistic regression for RR are reported in Table VI, where a significant association between RR, NICD and CD44 is shown. High levels of NICD or CD44 were found to be associated with progressive disease. Odds ratios (high levels vs. low levels) were 6.95 and 6.15 for NICD and CD44, respectively.

The following parameters: Clinical response to bevacizumab treatment, PFS and OS were not significantly different between patients with DLL4-positive and DLL4-negative tumors (data not shown).

Expression levels of angiogenesis-related genes in human colon cancer tissues. RT-qPCR analysis of the expression levels of ANGPT1, ANGPT2, DLL4, EGF, FGF1, FGF2, PGF and $V E G F$ did not reveal significant differences between the high and low NICD groups (Table VII).

\section{Discussion}

The present study evaluated the association of CD44 and DLL4 expression with NICD expression. Furthermore, their association with patient response to anti-VEGF therapy was examined in patients with advanced colon cancer. Although the current report is mainly exploratory, to the best of our knowledge, these findings are the first to indicate an association between NICD and CD44 expression and bevacizumab efficacy.

CSCs are induced and maintained under hypoxic conditions (34). The activation of Notch signaling may increase the self-renewal capacity of CSCs $(13,35)$ and initiate a CSC phenotype (36). Furthermore, CD44 serves a key role in regulating the properties of CSCs and in the cross talk with the tumor microenvironment $(37,38)$. The present study demonstrated that high NICD expression levels were significantly associated with strong CD44 staining. These results were in accordance with preclinical studies reporting that Notch target genes are highly expressed in colon crypts, and could regulate proliferation and migration in the colonic stem cell niche $(39,40)$. In addition, the present study demonstrated that the potential biological process associated with bevacizumab resistance in tumors expressing high NICD levels could be associated with the presence of colon tumor cells expressing CD44. These findings were derived from protein expression analysis in tumor tissue. In the present study, it was demonstrated that NICD and CD44 expression were significantly associated with poor response to bevacizumab-based treatment. To the best of our knowledge, this topic has not been previously addressed. It remains unclear whether CSCs may contribute to Notch signaling-mediated resistance to anti-VEGF therapy in patients with colon cancer. Therefore, such biomarkers may warrant validation in larger prospective studies, in order to demonstrate their efficacy in predicting the response to bevacizumab therapy in patients with advanced colon cancer.

DLL4 is an activator of Notch signaling, the expression of which is upregulated in tumor blood vessels (41), suggesting that DLL4 may be involved in NICD signaling via a paracrine loop. DLL4 induces endothelial proliferation and increases the development of the vascular network. MVD assessment is the most commonly employed technique to quantify intratumoral angiogenesis in cancer. Several retrospective studies have reported that MVD is inversely associated with survival in CRC $(42,43)$; however, this conclusion is not supported by other studies $(42,44,45)$. In the present study, no difference was noted in MVD between the high and low NICD groups of patients exposed to VEGF-targeted therapy, suggesting that MVD was 
not associated with survival in this cohort of patients with colon cancer. Furthermore, the data indicated that DLL4 expression was not significantly different between the high and low/absent NICD expression groups. DLL4 mRNA expression levels were also similar in the high and low/absent NICD expression groups; this phenomenon was also noted for various other angiogenesis-related genes. These findings further supported the histological analysis of microvessel distribution. Although several studies $(42,43,46)$ have reported a correlation between the expression levels of angiogenic factors and the prognosis of neoplastic disease, it must be stressed that the present analysis was carried out in a cohort of patients resistant to anti-VEGF therapy. It is therefore expected that the degree of angiogenesis observed in the groups with different NICD expression levels was similar. Therefore, it may be hypothesized that the unfavorable outcome of the response to first-line bevacizumab treatment demonstrated in the high NICD-expressing patients with CRC may be associated with biological features of cancer cell stemness rather than differences in angiogenic phenotype. The present study was retrospective and exploratory, and made use of non-validated biomarkers. Nevertheless, the selected biomarkers were tested in a homogeneous patient population treated with bevacizumab-based chemotherapy, excluding a selection bias. The availability of a limited number of samples with good quality RNA reduced the possibility of further analysis; however, the PCR data observed were in good agreement with the histological data. The cohort analyzed in this study was part of a population used in prospective controlled clinical trials.

In conclusion, the present study indicated that high NICD expression was significantly associated with high CD44 expression. The reduced effects of anti-angiogenic therapy on high NICD-expressing patients with colon cancer may be dependent on Notch-induced regulation of CSCs. These data may also suggest a role of colon CSCs in primary resistance to anti-angiogenic treatment. Additional studies are required to confirm the validity of these findings in a larger sample size of patients with CRC.

\section{Acknowledgements}

The authors would like to thank Professor Enrico Maria Silini, Head of the Unit of Pathological Anatomy of the University Hospital of Parma, for revising the analysis of the biomarker data and for critically reviewing the manuscript. The authors also thank Dr Roberta Camisa and Dr Elena Rapacchi from the Medical Oncology Unit of the University Hospital of Parma for their excellent assistance regarding the approval of the study protocol by the Ethics Committee. We acknowledge the financial donation by Davines, SpA, Parma.

\section{Funding}

No funding was received.

\section{Availability of data and materials}

The datasets used and/or analyzed during the current study are available from the corresponding author on reasonable request.

\section{Authors' contributions}

FN, CA, CB, LB, GP and RS designed the study. FN, CB, GP, $\mathrm{CA}, \mathrm{LB}, \mathrm{AS}$ and $\mathrm{LG}$ performed the research. FN, CA, CB, LB, AS, GP, RS and SC analyzed the data and wrote the manuscript. CL, IT, AB, MR, RP, GT, DM, FL, PC participated in the collection of patient data. All authors read and approved the final version of the manuscript.

\section{Ethics approval and consent to participate}

The present study was conducted according to a protocol approved by the institutional review board/independent ethics committee of the University Hospital of Parma, and patients provided written informed consent for their participation in the study.

\section{Patients consent for publication}

Not applicable.

\section{Competing interests}

The authors declare that they have no competing interests.

\section{References}

1. Hurwitz H, Fehrenbacher L, Novotny W, Cartwright T, Hainsworth J, Heim W, Berlin J, Baron A, Griffing S, Holmgren E, et al: Bevacizumab plus irinotecan, fluorouracil, and leucovorin for metastatic colorectal cancer. N Engl J Med 350: 2335-2342, 2004.

2. Bergers $G$ and Hanahan D: Modes of resistance to anti-angiogenic therapy. Nat Rev Cancer 8: 592-603, 2008.

3. Burger RA, Brady MF, Bookman MA, Fleming GF, Monk BJ, Huang H, Mannel RS, Homesley HD, Fowler J, Greer BE, et al: Incorporation of bevacizumab in the primary treatment of ovarian cancer. N Engl J Med 365: 2473-2483, 2011.

4. PerrenTJ,Swart AM,PfistererJ,Ledermann JA,Pujade-LauraineE, Kristensen G, Carey MS, Beale P, Cervantes A, Kurzeder C, et al: A Phase 3 trial of bevacizumab in ovarian cancer. N Engl J Med 365: 2484-2496, 2011.

5. Bu P, Chen KY, Chen JH, Wang L, Walters J, Shin YJ, Goerger JP, Sun J, Witherspoon M, Rakhilin N, et al: A microRNA miR-34aregulated bimodal switch targets Notch in colon cancer stem cells. Cell Stem Cell 12: 602-615, 2013.

6. Özgül Özdemir RB, Özdemir AT, Oltulu F, Kurt K, Yiğittürk G and Kirmaz C: A comparison of cancer stem cell markers and nonclassical major histocompatibility complex antigens in colorectal tumor and noncancerous tissues. Ann Diagn Pathol 25: 60-63, 2016.

7. Kreso A, O'Brien CA, van Galen P, Gan OI, Notta F, Brown AM, $\mathrm{Ng} \mathrm{K}$, Ma J, Wienholds E, Dunant C, et al: Variable clonal repopulation dynamics influence chemotherapy response in colorectal cancer. Science 339: 543-548, 2013.

8. de Sousa e Melo F, Kurtova AV, Harnoss JM, Kljavin N,Hoeck JD, Hung J, Anderson JE, Storm EE, Modrusan Z, Koeppen H, et al: A distinct role for $\mathrm{Lgr}^{+}$stem cells in primary and metastatic colon cancer. Nature 543: 676-680, 2017.

9. Cho SH, Park YS, Kim HJ, Kim CH, Lim SW, Huh JW, Lee JH and Kim HR: CD44 enhances the epithelial-mesenchymal transition in association with colon cancer invasion. Int J Oncol 41: 211-218, 2012.

10. Prasetyanti PR, Zimberlin CD, Bots M, Vermeulen L, Melo Fde S and Medema JP: Regulation of stem cell self-renewal and differentiation by Wnt and Notch are conserved throughout the adenoma-carcinoma sequence in the colon. Mol Cancer 12: 126 2013.

11. Bates RC, Edwards NS, Burns GF and Fisher DE: A CD44 survival pathway triggers chemoresistance via lyn kinase and phosphoinositide 3-kinase/Akt in colon carcinoma cells. Cancer Res 61: 5275-5283, 2001. 
12. Adorno-Cruz V, Kibria G, Liu X, Doherty M, Junk DJ, Guan D, Hubert C, Venere M, Mulkearns-Hubert E, Sinyuk M, et al: Cancer stem cells: Targeting the roots of cancer, seeds of metastasis, and sources of therapy resistance. Cancer Res 75: 924-929, 2015.

13. Van der Flier LG and Clevers H: Stem cells, self-renewal, and differentiation in the intestinal epithelium. Annu Rev Physiol 71: 241-260, 2009.

14. Srinivasan T, Walters J, Bu P, Than EB, Tung KL, Chen KY, Panarelli N, Milsom J, Augenlicht L, Lipkin SM, et al: NOTCH signaling regulates asymmetric cell fate of Fast- and Slow-cycling colon cancer-initiating cells. Cancer Res 76: 3411-3421, 2016.

15. Louvi A and Artavanis-Tsakonas S: Notch and disease: A growing field. Semin Cell Dev Biol 23: 473-480, 2012.

16. Bray SJ: Notch signalling: A simple pathway becomes complex. Nat Rev Mol Cell Biol 7: 678-689, 2006.

17. Li JL, Sainson RC, Oon CE, Turley H, Leek R, Sheldon H, Bridges E, Shi W, Snell C, Bowden ET, et al: DLL4-Notch signaling mediates tumor resistance to anti-VEGF therapy in vivo. Cancer Res 71: 6073-6083, 2011.

18. Negri FV, Crafa P, Pedrazzi G, Bozzetti C, Lagrasta C, Gardini G, Tamagnini I, Bisagni A, Azzoni C, Bottarelli L, et al: Strong Notch activation hinders bevacizumab efficacy in advanced colorectal cancer. Future Oncol 11: 3167-3174, 2015.

19. Dalerba P, Dylla SJ, Park IK, Liu R, Wang X, Cho RW, Hoey T, Gurney A, Huang EH, Simeone DM, et al: Phenotypic characterization of human colorectal cancer stem cells. Proc Natl Acad Sci USA 104: 10158-10163, 2007.

20. Nagano $\mathrm{O}$ and Saya $\mathrm{H}$ : Mechanismand biological significance of CD44 cleavage. Cancer Sci 95: 930-935, 2004.

21. Aruffo A, Stamenkovic I, Melnick M, Underhill CB and Seed B CD44 is the principal cell surface receptor for hyaluronate. Cell 61: 1303-1313, 1990.

22. Lv L, Liu HG, Dong SY, Yang F, Wang QX, Guo GL, Pan YF and Zhang XH: Upregulation of CD44v6 contributes to acquired chemoresistance via the modulation of autophagy in colon cancer SW480 cells. Tumour Biol 37: 8811-8824, 2016.

23. Pan T, Xu J and Zhu Y: Self-renewal molecular mechanisms of colorectal cancer stem cells. Int J Mol Med 39: 9-20, 2017.

24. Mousa L, Salem ME and Mikhail S: Biomarkers of angiogenesis in colorectal cancer. Biomark Cancer 7 (Suppl 1): S13-S19, 2015.

25. Sobrero A, Ackland S, Clarke S, Perez-Carrión R, Chiara S, Gapski J, Mainwaring P, Langer B and Young S; AVIRI Trial investigators: Phase IV study of bevacizumab in combination with infusional fluorouracil, leucovorin and irinotecan (FOLFIRI) in first-line metastatic colorectal cancer. Oncology 77: 113-119, 2009.

26. Cunningham D, Lang I, Marcuello E, Lorusso V, Ocvirk J, Shin DB, Jonker D, Osborne S, Andre N, Waterkamp D, et al: Bevacizumab plus capecitabine versus capecitabine alone in elderly patients with previously untreated metastatic colorectal cancer (AVEX): An open-label, randomized phase 3 trial. Lancet Oncol 14: 1077-1085, 2013.

27. Loupakis F, Cremolini C, Masi G, Lonardi S, Zagonel V, Salvatore L, Cortesi E, Tomasello G, Ronzoni M, Spadi R, et al: Initial therapy with FOLFOXIRI and bevacizumab for metastatic colorectal cancer. N Engl J Med 371: 1609-1618, 2014.

28. Passardi A, Nanni O, Tassinari D, Turci D, Cavanna L, Fontana A, Ruscelli S, Mucciarini C, Lorusso V, Ragazzini A, et al: Effectiveness of bevacizumab added to standard chemotherapy in metastatic colorectal cancer: Final results for first-line treatment from the ITACa randomized clinical trial. Ann Oncol 26 1201-1207, 2015.

29. Eisenhauer EA, Therasse P, Bogaerts J, Schwartz LH, Sargent D, Ford R, Dancey J, Arbuck S, Gwyther S, Mooney M, et al: New response evaluation criteria in solid tumours: Revised RECIST guideline (version 1.1). Eur J Cancer 45: 228-247, 2009.
30. Bossi P, Viale G, Lee AK, Alfano R, Coggi G and Bosari S: Angiogenesis in colorectal tumors: Microvessel quantitation in adenomas and carcinomas with clinicopathological correlations. Cancer Res 55: 5049-5053, 1995.

31. Pfaffl MW, Horgan GW and Dempfle L: Relative expression software tool (REST) for group-wise comparison and statistical analysis of relative expression results in real-time PCR. Nucleic Acids Res 30: e36, 2002.

32. Hosmer DW, Lemeshow S and May S: Applied Survival analysis: Regression modeling of time-to-event data. 2nd edition. John Wiley \& Sons Inc., Hoboken, NJ, 2008.

33. Mills M: Introducing survival and Event History analysis. 1st edition. Sage Publications Ltd., London, 2011.

34. Papaccio F, Paino F, Regad T, Papaccio G, Desiderio V and Tirino V: Concise review: Cancer cells, cancer stem cells, and mesenchymal stem cells: Influence in cancer development. Stem Cells Transl Med 6: 2115-2125, 2017.

35. Blank U, Karlsson G and Karlsson S: Signaling pathways governing stem-cell fate. Blood 111: 492-503, 2008.

36. Wang P, Lan C, Xiong S, Zhao X, Shan Y, Hu R, Wan W, Yu S, Liao B, Li G, et al: HIF1 $\alpha$ regulates single differentiated glioma cell dedifferentiation to stem-like cell phenotypes with high tumorigenic potential under hypoxia. Oncotarget 8 : 28074-28092, 2017.

37. Williams K, Motiani K, Giridhar PV and Kasper S: CD44 integrates signaling in normal stem cell, cancer stem cell and (pre) metastatic niches. Exp Biol Med 238: 324-338, 2013.

38. Ponta H, Sherman L and Herrlich PA: CD44: From adhesion molecules to signalling regulators. Nat Rev Mol Cell Biol 4: 33-45, 2003.

39. Riccio O, van Gijn ME, Bezdek AC, Pellegrinet L, van Es JH, Zimber-Strobl U, Strobl LJ, Honjo T, Clevers H and Radtke F: Loss of intestinal crypt progenitor cells owing to inactivation of both Notch1 and Notch2 is accompanied by derepression of CDK inhibitors p2 $7^{\mathrm{Kip1}}$ and p57 $7^{\mathrm{Kip} 2}$. EMBO Rep 9: 377-383, 2008.

40. Pellegrinet L, Rodilla V, Liu Z, Chen S, Koch U, Espinosa L, Kaestner KH, Kopan R, Lewis J and Radtke F: Dll1- and dll4-mediated notch signaling are required for homeostasis of intestinal stem cells. Gastroenterology 140: 1230-1240.e1-e7, 2011.

41. Li JL, Sainson RC, Shi W, Leek R, Harrington LS, Preusser M, Biswas S, Turley H, Heikamp E, Hainfellner JA, et al: Delta-like 4 Notch ligand regulates tumor angiogenesis, improves tumor vascular function, and promotes tumor growth in vivo. Cancer Res 67: 11244-11253, 2007

42. Des Guetz G, Uzzan B, Nicolas P, Cucherat M, Morere JF, Benamouzig R, Breau JL and Perret GY: Microvessel density and VEGF expression are prognostic factors in colorectal cancer. Meta-analysis of the literature. Br J Cancer 94: 1823-1832, 2006.

43. Sundov Z, Tomic S, Alfirevic S, Sundov A, Capkun V, Nincevic Z, Nincevic J, Kunac N, Kontic M, Poljak N and Druzijanic N: Prognostic value of MVD, LVD and vascular invasion in lymph node-negative colon cancer. Hepatogastroenterology 60: 432-438, 2013

44. Gao J, Knutsen A, Arbman G, Carstensen J, Frånlund B and Sun XF: Clinical and biological significance of angiogenesis and lymphan-giogenesis in colorectal cancer. Dig Liver Dis 41: 116-122, 2009

45. Zygoń J, Szajewski M, Kruszewski WJ and Rzepko R: VEGF, Flt-1, and microvessel density in primary tumors as predictive factors of colorectal cancer prognosis. Mol Clin Oncol 6: 243-248, 2017.

46. Custodio A, Barriuso J, de Castro J, Martínez-Marín V, Moreno V, Rodríguez-Salas N and Feliu J: Molecular markers to predict outcome to antiangiogenic therapies in colorectal cancer: Current evidence and future perspectives. Cancer Treat Rev 39: 908-924, 2013. 